\title{
Consequences of Coronavirus as a Predictor of Emotional Security among Mothers of Children with Intellectual Disabilities
}

\author{
Suad M.O. Abuzaid
}

Taibah University, Special Education, Saudi Arabia

\begin{abstract}
Parents of children with intellectual disability (ID) suffer from comparatively emotional insecurity compared to parents of children without ID, especially during periods of crisis, such as the outbreak of coronavirus pandemic. This study aimed to investigate the consequences of Coronavirus as a predictor of emotional security among mothers of children with intellectual disabilities. Mothers of children with intellectual disabilities were considered for data collection. The study group of the research consists of 120 mothers who have children with intellectual disabilities. They aged 23-55 years, $(M=43.23, S E=0.075)$. Consequences of Coronavirus Questionnaire $(C C Q-20)$ and Emotional Security Scale (ESS-20) were used to collect and analyze data. For this study, quantitative survey research was employed. The independent variable is the consequences of Coronavirus, and emotional security is the dependent variable. The independent variable is the consequences of Coronavirus, and emotional security is the dependent variable. To test the hypotheses of the study, Pearson correlation and Linear regression analysis were conducted. Findings indicate that the independent variable (Coronavirus) contributed to the prediction of emotional security among mothers of children with intellectual disabilities. Findings of the current study indicate that the greater the Consequences of Corona, the less emotionally secure the mother is likely to feel during the COVID-19 lockdown in Saudi Arabia.
\end{abstract}

Keywords: Child behaviors, child's mental health, Coronavirus, emotional maturity, feeling optimistic, intellectual disabilities.

\section{INTRODUCTION}

Intellectual disability (ID) is regarded as a disorder that starts at the developmental period. Children with this disorder are said to have intellectual and adaptive functioning deficits in conceptual, social, and practical domains [1-9]. These children are said to have generally poorer coping abilities [10], and that is why they likely to have great burden because of the Coronavirus pandemic, as their mental health is impaired and deeply affected according to the social distancing and isolation measures, which were implemented to manage the pandemic [11-12]. Thus, this group of children is at specific risk during the COVID-19 coronavirus pandemic because of marked mental and physical health multimorbidity $[10,13]$.

The Corona pandemic, with its effects and repercussions, represented a major catastrophe for societies in a way that the world has never seen, except in the light of the major crises and disasters that have passed through history, and children in general and children with disabilities, in particular, are among the groups most affected by the ban imposed on them by this virus [14-15].

Although much of the literature indicated that children are less likely to be infected with the Coronavirus, they are more affected by psychological and social aspects, as isolating children in homes represents a greater psychological burden than the

*Address correspondence to this author at the Taibah University, Special Education, Saudi Arabia; Tel: +966594442822;

E-mail: sabuzaid@taibahu.edu.sa physical suffering caused by the virus, so the closure of schools and the lack of exposure of children to the air and the exercise of their beloved activities changing sleep habits, and the usual lifestyle, can lead to these children feeling lonely, upset, distressed, and various neuropsychiatric manifestations [16].

And if this is the psychological effect of the virus on ordinary children, how will this effect be on children with disabilities? Children with disabilities were prevented from receiving care and achieving goals at the hands of specialists because the rehabilitation centers stopped carrying out their role, and they were deprived of leaving home and the medical care that they need (Zero), and to the emergence of some bad appearances and behaviors that he was supposed to get rid of during rehabilitation [17].

Of course, the delays experienced by children with disabilities reflected negatively on the mother's feeling of emotional security, so anxiety and fear associated with grief over her son haunted her all the time. After her son was making even simple steps, he is now deprived of all this, and it may have caused him a setback, which is reflected in the mother's feeling of safety and security.

\section{LITERATURE REVIEW}

The Effects of the Corona Pandemic on Children with Intellectual Disabilities

Children with mental disabilities have not been spared from the effects of COVID-19, research and 
studies have indicated various effects, as people with mental disabilities usually show a specific daily routine in which any deviation leads to a moderate to the severe feeling of anxiety and tension, which was evident in the spread phase. Corona, as governments worldwide have implemented strict lockdown measures without taking into account these children, people with mental disabilities have been largely forgotten. The lockdown, virtual learning, and wearing masks in the open air led to severe disruptions in the lives of these children. Government officials rarely treated This large population is at risk in public health protocols [18].

The COVID-19 pandemic has brought about significant stress and anxiety for many parents worldwide [19]. The lack of support from services, family, and the community for those who need it the most had a significant negative impact on the mothers, as Gemma et al. [18] indicated. All of the mothers in our study experienced lockdown as a time of stress. They reported feeling abandoned, stigmatized, and experienced an increase in mental health problems during the first lockdown period. They reported living in a state of fear, navigating an unpredictable, inescapable home environment [18].

Because the need for these groups of children to rehabilitate services and the negative effects, represented as obstacles to the education and rehabilitation process resulting from the epidemic, many countries have attempted to adapt education using various networks and virtual education. Many academies and schools have turned into platforms for online education. These institutions provide training sessions via the Internet, which requires children with mental disabilities and their families to make major adjustments in their lives and how they are rehabilitated as an alternative to completely stopping the rehabilitation process $[20,21]$.

Attempts to help children with disabilities cope with the disruption caused by the COVID-19 pandemic have not stopped, many studies and reviews have been published on ways to help these individuals; especially those with mental disabilities, which relied on organizing their daily schedule and using various activities using the blackboard or finding new activities to play. And schedule these activities at specific times throughout the day. Several video/computer games have been suggested to help these kids. Nevertheless, parents need to know what is best for their children to help arrange these activities in a daily schedule that reduces any resistance or distress resulting from the sudden changes caused by the pandemic [22].

\section{Emotional Security of Mothers of Children with Disabilities during Corona Pandemic}

Emotional security is a requirement or a basic motivation of the living being in general, and the human being in particular, where the motive of fear and the desire to feel secure lies behind much of what we do in terms of behavior, such as fleeing from sources of danger, or serious and diligent in achieving so that the status of the individual rises, and increases his income secures his future and guarantees his basic need, for the sense of tranquility is an internal psychological state in which the individual feels safe and calm, and externally represented in achieving most of his demands and satisfying most of his condition and the spread of the spirit of psychological satisfaction, the individual's self-acceptance, his sense of achievement, and his true participation in activities that achieve and support him this feeling [23].

The presence of a disabled child in the family represents psychological pressure on family members in general and, particularly, on the mothers of these children. The parents of an unusual child are subjected to multiple pressures due to the deficiencies that this child shows and his complete dependence on them, and these pressures are represented in the pressures related to cognitive problems, for the child, pressures related to behavioral problems him, pressures related to the child's financial burdens, pressures related to fear for the child's future, and pressures that arise as a result of blaming one parent to the other for being the reason for the child's disability [24].

And suppose mothers of children with disabilities suffer from all these pressures on their normal day due to the presence of a disabled child. What is the case when these pressures increase as a result of the consequences of the Corona pandemic?

The Corona pandemic suddenly spread, which made everyone live in difficult times, negatively affecting most people, but indeed the largest share was for those who suffer from challenges and disabilities, and also on the families of these children, especially the families of children with mental disabilities. The Corona epidemic has affected and continues to negatively affect all children, whether disabled or ordinary, as a result of being deprived of the routine of practicing their normal lives and all activities that they used to do outside the home in their normal daily life, and there is no doubt that this also represents a great burden on their families, especially mothers because of 
the increase in the size of the role that they have to play to reduce the negative effects of this period on their children [25].

One of the first challenges that families of disabled children face, especially mothers, is the child's sudden change when he stopped going to school or the center. Then the issue of his education or treatment ceased, it is known that these children need individual, codified and customized intervention for each child according to his needs. It is not appropriate for him to receive the information visible and audible remotely, rather he needs a person with him continuously. The challenge also faced by the families of these children is preventing them from movement play, which is an integral part of their daily routine. They were deprived of that for a not short time, which caused great psychological pressure on these children and their families [26].

\section{PROBLEM STATEMENT}

The Corona pandemic negatively affected everyone. This effect is not material, economic, and social but also extended to psychological aspects as well. It is not limited to adults only, but also to young children deprived of all entertainment and activities they used to practice. So, everyone lived in a state of terror, fear, and constant anxiety. If this clarity is for everyone, what is the situation for children with disabilities, and how is it for their mothers?

This study poses the following hypotheses:

Hypothesis 1: There are significant correlations between consequences of Coronavirus and emotional security among mothers of children with intellectual disabilities.

Hypothesis 2: There is a significant effect consequence of Coronavirus on emotional security among mothers of children with intellectual disabilities.

Hypothesis 3: There is a relative contribution of consequences of Coronavirus to emotional security among mothers of children with intellectual disabilities.

\section{METHOD}

\section{Design}

For this study, quantitative survey research was employed. The independent variable is the consequences of Coronavirus, and emotional security is the dependent variable.

\section{Participants}

In order to meet the primary objective, only mothers of children with intellectual disabilities were considered for data collection. The study group of the research consists of 120 mothers who have children with intellectual disabilities. They aged 23-55 years, ( $M=$ 43.23, $S E=0.075$ ). Surveys were administered electronically. Mothers' participation in the study was voluntary, anonymity was guaranteed. Anonymous online survey instruments were developed to keep personal information confidential and circulated through online communication, i.e., Facebook messenger, Facebook public group of the target population, personal e-mail. Those who did not fill in the whole forms of the surveys were excluded. Thus, 120 forms of the surveys were recorded for the final analysis.

\section{Instruments}

The researcher used the Consequences of Coronavirus Questionnaire (CCQ-20). In order to develop the questionnaire, the researcher reviewed theoretical frameworks and previous studies that dealt with the consequences of the Corona pandemic in general and especially in the field of special education. The researcher also conducted a survey study on several mothers $(n=80)$ of children with intellectual disabilities. They were asked to answer the following question: What are the consequences of the Corona pandemic from your point of view on your children? After the mothers' response to the question, the researcher analyzed these responses to try to determine the dimensions of Consequences of the Coronavirus Questionnaire as perceived by mothers of children with intellectual disabilities, and the researcher reached a set of dimensions (rehabilitation/child behaviors / the child's mental health). The purpose of this questionnaire was to assess the consequences of Coronavirus on children with intellectual disabilities. It is 20 items with a 5 -point Likert scale from $1=$ strongly disagree, $5=$ strongly agree. The scale takes only 10 minutes to complete. The scale's reliability was calculated using internal consistency reliability (Cronbach's $\alpha=0.88$ ) and split-half reliability (Spearman-Brown $=0.86$ ). The author used Construct validity. The CCQ-20 is significantly correlated in the expected direction with Impact of Event Scale (IES) [27] $(r=0.32, p<0.05)$. A group of 10 experts examined the content validity of the scale. They assessed the relevance of each item using a four-point Likert scale (where 1 represents "irrelevant" and 4 represents "highly relevant"). They provided 
suggestions and comments. The 20 items were judged to be quite or highly relevant. A content validity index was calculated at the item level $(I-C V I=0.90)$.

Emotional Security Scale (ESS-20 By the researcher). In order to develop the Questionnaire, the researcher reviewed theoretical frameworks and previous studies that dealt with emotional security. The researcher also conducted a survey study on several mothers $(n=80)$ of children with intellectual disabilities. They were asked to answer the following question: How do you feel as a mother of a child of handicap? After the mothers' response to the question, the researcher analyzed these responses to determine the dimensions of the Emotional Security Scale. The researcher reached a set of dimensions (Feeling satisfied / Feeling optimistic / Emotional maturity). It is 20 items with a 5-point Likert scale from $1=$ strongly disagree, $5=$ strongly agree. The scale takes only 10 minutes to comscale's reliabilityf the scale was calculated using internal consistency reliability (Cronbach's s $\alpha=0.87$ ) and split-half reliability (Spearman-Brown $=.83$ ). The author used Construct validity. The ESS-20 is significantly correlated in the expected direction with Emotional Security Scale [28] $(r=0.22, p<0.05)$. A group of 10 experts examined the content validity of the scale. They assessed the relevance of each item using a four-point Likert scale (where 1 represents "irrelevant" and 4 represents "highly relevant"). They provided suggestions and comments. The 20 items were judged to be quite or highly relevant. A content validity index was calculated at the item level $(\mathrm{I}-\mathrm{CVI}=0.90)$.

\section{Statistical Analysis}

To test the hypotheses of the study, Pearson correlation and Linear regression analysis were conducted.

\section{RESULTS}

Table 1 shows the means, descriptive statistics, inter-correlations, and internal consistency coefficients of Consequences of Coronavirus (rehabilitation / child behaviors / the child's mental health) and Emotional Security (Feeling satisfied / Feeling optimistic / Emotional maturity). All Consequences of Coronavirus dimensions (rehabilitation / child behaviors / the child's mental health) correlated negatively with all dimensions of Emotional Security (Feeling satisfied / Feeling optimistic / Emotional maturity) ( $r=-0.29 /-0.34 /$ - 0.31) respectively. $p<0.01$

Results presented in Table 2 show that the independent variable (Consequences of Coronavirus) yielded a coefficient of linear regression $(R)$ of 0.631

Table 1: Inter-Correlations of Consequences of Coronavirus (Rehabilitation/Child Behaviors / the Child's Mental Health) and Emotional Security(Feeling Satisfied / Feeling Optimistic / Emotional Maturity)

\begin{tabular}{|c|c|c|c|c|c|c|}
\hline Variables & 1 & 2 & 3 & 4 & 5 & 6 \\
\hline $\mathrm{RH}$ & 1.00 & $0.54^{* *}$ & $0.56^{* *}$ & $-0.29^{* *}$ & $-0.34^{* *}$ & $-0.31^{* *}$ \\
\hline CB & $0.54^{* *}$ & 1.00 & $0.53^{* *}$ & $-0.27^{\star *}$ & $-0.31^{* *}$ & $-0.32^{* *}$ \\
\hline $\mathrm{CMH}$ & $0.56^{\star \star}$ & $0.53^{* *}$ & 1.00 & $-0.26^{* *}$ & $-0.30^{* *}$ & $-0.33^{* *}$ \\
\hline FS & $-0.29^{* *}$ & $-0.27^{\star *}$ & $-0.26^{\star *}$ & 1.00 & $0.60^{* *}$ & $0.53^{* *}$ \\
\hline FO & $-0.34^{* *}$ & $-0.31^{* *}$ & $-0.30^{\star *}$ & $0.60^{* *}$ & 1.00 & $0.53^{* *}$ \\
\hline EM & $-0.31^{* *}$ & $-0.32^{\star *}$ & $-0.33^{\star *}$ & $0.53^{\star \star}$ & $0.53^{\star *}$ & 1.00 \\
\hline Mean & 22.26 & 20.45 & 33.12 & 28.11 & 26.27 & 28.01 \\
\hline SD & 2.33 & 4.21 & 4.01 & 3.81 & 4.22 & 4.08 \\
\hline
\end{tabular}

Note: $\mathrm{RH}=$ rehabilitation, $\mathrm{CB}=$ child behaviors, $\mathrm{CMH}=$ the child's mental health, $\mathrm{FS}=$ Feeling satisfied, $\mathrm{FO}=$ Feeling optimistic, $\mathrm{EM}=\mathrm{Emotional}$ maturity . Note. ${ }^{* *} p<0.01$

Table 2: The Regression Result of the Predictor Variable (Consequences of Coronavirus) and the Outcome Measure (Emotional Security). Model Summary

\begin{tabular}{|c|c|c|c|c|c|c|c|c|c|}
\hline \multirow{2}{*}{ Model } & \multirow{2}{*}{$\mathbf{R}$} & \multirow{2}{*}{ R Square } & \multirow{2}{*}{$\begin{array}{l}\text { Adjusted R } \\
\text { Square }\end{array}$} & \multirow{2}{*}{$\begin{array}{c}\text { Std. Error of the } \\
\text { Estimate }\end{array}$} & \multicolumn{5}{|c|}{ Change Statistics } \\
\hline & & & & & $\begin{array}{l}\text { R Square } \\
\text { Change }\end{array}$ & F Change & df1 & df2 & Sig. F Change \\
\hline
\end{tabular}

${ }^{\text {a }}$ Predictor: (Constant) CC

${ }^{b}$ Dependent Variable: ES. 
Table 3: Summary of Linear Regression Analysis between the Predictor Variable (Consequences of Coronavirus)and the Outcome Measure (Emotional Security). ANOVA

\begin{tabular}{|c|c|c|c|c|c|c|}
\hline \multicolumn{2}{|c|}{ Model } & Sum of Squares & df & Mean Square & F & Sig. \\
\hline \hline \multirow{2}{*}{1} & Regression & 2489.024 & 1 & 1244.512 & 108.824 & $0.000^{\text {a }}$ \\
\cline { 2 - 7 } & Residual & 1452.368 & 118 & 11.436 & & \\
\cline { 2 - 7 } & Total & 3941.392 & 119 & & & \\
\hline
\end{tabular}

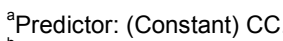

bependent Variable: ES.

Table 4: Relative Contribution of the Independent Variable to the Prediction of Emotional Security Coefficients

\begin{tabular}{|c|c|c|c|c|c|c|c|c|}
\hline & \multirow{2}{*}{ Model } & \multicolumn{2}{|c|}{$\begin{array}{l}\text { Unstandardized } \\
\text { Coefficients }\end{array}$} & \multirow{2}{*}{$\begin{array}{c}\begin{array}{c}\text { Standardized } \\
\text { Coefficients }\end{array} \\
\text { Beta }\end{array}$} & \multirow[t]{2}{*}{ t } & \multirow[t]{2}{*}{ Sig. } & \multicolumn{2}{|c|}{$95.0 \%$ Confidence Interval for B } \\
\hline & & B & Std. Error & & & & Lower Bound & Upper Bound \\
\hline \multirow[t]{2}{*}{2} & (Constant) & 9.973 & 1.706 & & 5.846 & 0.000 & 6.597 & 13.349 \\
\hline & $\mathrm{CC}$ & 0.359 & 0.066 & 0.461 & 5.424 & 0.000 & 0.228 & 0.490 \\
\hline
\end{tabular}

aDependent Variable: ES

and a multiple correlation square of 0.626 . This shows that $62.6 \%$ of the total variance in Emotional Security of those who participated in the study is accounted for by Consequences of Coronavirus. Table 3 indicates that the analysis of variance of the linear regression data produced an F-ratio value significant $p<0.01(F(2,118)$ $=108.824 ; \mathrm{P}<0.01)$.

As for results displayed in Table 4, the independent variable made a significant contribution to the prediction of Emotional Security. The results indicated that the following beta weight, which represented the relative contribution of the independent variable to the prediction, was observed. Consequences of Coronavirus $(b=0.359, t=5.424, P<0.01)$.

\section{DISCUSSION}

The purpose of this study was to investigate the Consequences of Coronavirus as a predictor of emotional security among mothers of children with intellectual disabilities. Findings indicated that all Consequences of Coronavirus dimensions (rehabilitation/child behaviors / the child's mental health) correlated negatively with all dimensions of Emotional Security (Feeling satisfied / Feeling optimistic / Emotional maturity).

The existence of a negative correlation between the Consequences of the Corona pandemic as perceived by mothers of children with intellectual disabilities and their emotional security, that is, the greater the Consequences of Corona, the less emotionally secure the mother are likely to feel. The level of emotional security can be predicted from the level of mothers' awareness of the Consequences of the Corona pandemic on their children with intellectual disabilities. The result is reasonable and logically acceptable, that the Corona pandemic brought many negative effects on all human beingsn [19-26]. Perhaps the most important of these Consequences was the stop of most activities that individuals were practicing. If ordinary children were affected by these Consequences, what would be the case for children with disabilities and their families? The COVID-19 pandemic has led to a heavy reliance on informal home care provision [18]. A substantial body of evidence highlights the difficulties that family carers experience in 'normal' times when supporting a child with intellectual disabilities, including experiences of depression, stress and carer burden and the need they have of a supportive environment, particularly if economically disadvantaged [10-11, 17-18]. Corona pandemic led to the stop of rehabilitation of children with disabilities, and then regression in some behaviors and even some undesirable behaviors. These children also became more angry and violent, and then it became difficult to control them. There is no doubt that all of these Consequences on children with disabilities show their mother's many psychological pressures. The psychological pressure was only the financial burdens and burdens of her child's presence with her all the time, but this pressure extended to fear and anxiety on her children. The psychological and behavioral aspects of them, which began to deteriorate with the extension of the Corona pandemic, affected mothers' feelings of fear, anxiety, the inability to 
emotional maturity, loss of hope, and even loss of a sense of security.

This result was in agreement with the results of Ahmed and Al-Roubi's study [29], whose results indicated that one of the negative consequences that resulted from the Corona pandemic and affected the families of these children with disabilities and made them lose a sense of security, feeling psychological pressure due to the presence of the disabled child inside the house all day. The child's level of communication decreased, the difficulty in caring for the child himself, the feeling of distress in the inability to form proper feeding, speech, sleep habits, anger when the child practiced unacceptable behaviors, and the child's isolation and withdrawal from social participation.

Suddenly the rehabilitation stopped, and the process of communicating with caregivers stopped, which may lead to a retreat in the child's abilities. Not only that, the rehabilitation process for children with disabilities is stopped, one of the important points that add to the stress of the family.

\section{CONCLUSIONS}

In conclusion, the negative consequences resulting from the Corona pandemic affected the families of these children with disabilities and made them lose a sense of security, the feeling of psychological pressure due to the presence of the disabled child inside the house all day. The COVID-19 pandemic has brought about significant stress and anxiety for many parents around the world. The lack of support from services, family, and the community for those who need it the most negatively impacted the mothers. There is no doubt that the COVID-19 pandemic triggered significant changes in the lives of many informal carers of children with intellectual disabilities, and the impact of those changes is yet to be fully determined. Mothers of children with intellectual disabilities face difficulties managing daily activities during the COVID-19 outbreak as their children with intellectual disabilities presented challenging behaviors, and education, healthcare and respite services, and other professional support were limited or not available. Interventions to promote emotional wellbeing and to protect parents against adverse outcomes should be informed by a resilience perspective and can often consist of strengthening supportive factors in the social ecology of the parent. The child's level of communication decreased, the difficulty in caring for the child himself, the feeling of distress in the inability to form proper feeding, speech, sleep habits, anger when the child practiced unacceptable behaviors, and the child's isolation and withdrawal from social participation.

\section{ACKNOWLEDGEMENT}

The author would like to express her very great appreciation to mothers for their consent to participate.

\section{CONFLICT OF INTEREST}

The author declares that she has no conflict of interest.

\section{REFERENCES}

[1] American Psychiatric Association. Diagnostic and Statistical Manual of mental disorders. Washington DC: APA 2013; 51. https://doi.org/10.1176/appi.books.9780890425596

[2] Bartnikowska U, Ćwirynkało K, Borowska-Beszta B. A Pattern of Transition to Adulthood Indicated in Plans for the Future of Males With Intellectual Disabilities: Secondary Qualitative Data Analysis. Psycho-Educ Res Rev 2017; 6(1): 51-56.

[3] Saad MAE, EIAdI AM. Defining and Determining Intellectual Disability (Intellectual Developmental Disorder): Insights from DSM-5. Psycho-Educ Res Rev 2019; 8(1): 51-54.

[4] Khalik ASA. The Effectiveness of a Phonological Awareness Training Intervention on Phonological Working Memory of Children with Intellectual Disabilities. Psycho-Educ Res Rev 2014; 3(1): 50-55.

[5] Hasanin H. The Effect of Social Information Processing Model Training on Improving Social Behaviour of With Intellectual Disabilities. Psycho-Educ Res Rev 2015; 4(1): 10-22.

[6] Ćwirynkało K, Beata B, Urszula B. Masculinity As Defined by Males Self-Advocates With Intellectual Disabilities: A Focus Group Research Report. Psycho-Educ Res Rev 2016; 5(3): 36-50.

[7] Eissa MA, Al Huseini HH. Effect of Multisensory Approach on Increasing Math Skills Children With Mild Intellectual Disabilities. Psycho-Educ Res Rev 2013; 2(3): 73-82.

[8] Szczupał B. Incapacitation As a Mean of Protecting the Dignity of the Persons With Disabilities in the View of Convention on the Rights of Persons With Disabilities. Psycho-Educ Res Rev 2017; 6(1): 1-9.

[9] Baczała D. Social Skills of Individuals With Intellectual Disabilities. Psycho-Educ Res Rev 2016; 5(2): 68-77.

[10] Courtenay K, Perera B. COVID-19 and people with intellectual disability: Impacts of a pandemic. Irish J Psych Medic 2020; 37(3): 231-236.

https://doi.org/10.1017/ipm.2020.45

[11] Brooks SK, Webster RK, Smith LE, Woodland L, Wessely S, Greenberg N, Rubin GJ. The psychological impact of quarantine and how to reduce it: Rapid review of the evidence. Lancet 2020; 395: 912-920. https://doi.org/10.1016/S0140-6736(20)30460-8

[12] Torales J, O'Higgins M, Castaldelli-Maia JM, Ventriglio A. The outbreak of COVID-19 Coronavirus and its impact on global mental health. Intern J Soc Psychiat 2020; 66: 317320. https://doi.org/10.1177/0020764020915212

[13] Turk MA, Landes SD, Formica MK, Goss KD. Intellectual and developmental disability and COVID-19 case-fatality trends: 
TriNetX analysis [published online ahead of print, May 24, 2020].

[14] Altun T, Salih A, Ahmet G, Caner Ö. Investigating Education Faculty Students' Views about Asynchronous Distance Education Practices During Covid-19 Isolation Period. Psycho-Educ Res Rev 2021; 10(1): 34-45.

[15] Bilgin O, Erhan Y. Perceptions of University Students about Coronavirus: A Metaphor Analysis Study. Psycho-Educ Res Rev 2021; 10(1): 118-27.

[16] Torales J, O'Higgins M, Castaldelli-Maia JM, Ventriglio A. The outbreak of COVID-19 Coronavirus and its impact on global mental health. Intern J Soc Psychiat 2020; 66: 317320. https://doi.org/10.1177/0020764020915212

[17] Varsha P, Gisela P, Biza S, Gemma R, John R, Glynis M, Vivien C, Peter E, Steve H, Clair C, Paul W, The Experiences of Carers of Adults With Intellectual Disabilities During the First COVID-19 Lockdown Period. J Polic Pract Intell Disab 2021.

[18] Gemma R, Gisela Pe, Biza S, Varsha P, Glynis M, John R, Vivien C, Peter E, Steve H, Clair Clifford, Paul W. The experiences of mothers of children and young people with intellectual disabilities during the first COVID-19 lockdown period. J Appl Res Intell Disab 2021.

[19] Coyne LW, Gould ER, Grimaldi M, Wilson KG, Baffuto G, Biglan A. First Things First: Parent Psychological Flexibility and Self-Compassion During COVID-19. Behav Analy Pract 2020.

https://doi.org/10.1007/s40617-020-00435-w

[20] Cahapay MB. How Filipino Parents Home Educate their Children with Autism during COVID-19 Period. Intern J Devel Disab 2020. https://doi.org/10.1080/20473869.2020.1780554

[21] Cahapay MB. Ushering children with disabilities in the 'new normal' post-COVID-19 period: collective actions in the Philippines. Disab Soc 2021; 36(1): 145-150. https://doi.org/10.1080/09687599.2020.1829557
[22]

Narzisi A. Handle the Autism Spectrum Condition During Coronavirus (COVID-19) Stay At Home period: Ten Tips for Helping Parents and Caregivers of Young Children. Brain Sci 2020; 10(4): 207.

https://doi.org/10.3390/brainsci10040207

[23] Jiang S, Zhang H, Qi J, Fang B, Xu T. Perceiving SocialEmotional Volatility and Triggered Causes of COVID-19. Int J Environ Res Public Health 2021; 18: 4591. https://doi.org/10.3390/ijerph18094591

[24] Spinelli M, Lionetti F, Pastore M, Fasolo M. Parents' Stress and Children's Psychological Problems in Families Facing the COVID-19 Outbreak in Italy. Front Psychol 2020; 11: 1713.

https://doi.org/10.3389/fpsyg.2020.01713

[25] Patricia N, Antonio M, Manuela C, Zofia W, Miguel Á. Verdugo, Supports for People with Intellectual and Developmental Disabilities during the COVID-19 pandemic from their Own Perspective. Res Devel Disab 2020; 103813. https://doi.org/10.1016/j.ridd.2020.103813

[26] Arianna B, Noemi M, Michele G, Paola V, Simona de. Psychological impact of Covid-19 pandemic in Italian families of children with neurodevelopmental disorders. Res Devel Disab 2021; 109: 103840.

https://doi.org/10.1016/j.ridd.2020.103840

[27] Zhang Y, Ma ZF. Impact of the COVID-19 Pandemic on Mental Health and Quality of Life among Local Residents in Liaoning Province, China: A Cross-Sectional Study. Int J Environ Res Public Health 2020; 17(7): 2381 https://doi.org/10.3390/ijerph17072381

[28] Choucair Z. Emotional reassurance scale. Cairo: The AngloEgyptian Library 2005.

[29] Ahmed S, Al-Roubi S. Challenges facing families of children with neurodevelopmental disorders at home in light of the Corona pandemic. Spec Rehab 2020; 10(38): 151-18. https://doi.org/10.21608/sero.2020.120438

\section{https://doi.org/10.6000/2292-2598.2021.09.04.6}

(C) 2021 Suad M.O. Abuzaid; Licensee Lifescience Global.

This is an open access article licensed under the terms of the Creative Commons Attribution Non-Commercial License (http://creativecommons.org/licenses/by-nc/3.0/) which permits unrestricted, non-commercial use, distribution and reproduction in any medium, provided the work is properly cited. 